\title{
Massive necrosis of the colon due to amoebiasis
}

\author{
D. M. ESSENHIGH AND R. L. CARTER \\ From the Radcliffe Infirmary, Oxford
}

EDITORIAL COMMENT This case report is included to remind British readers that amoebiasis can occur in patients who have not visited areas in which amoebiasis is common and that the illness may present acutely with unexpected features.

Amoebiasis is thought of as a rare disease in Britain, and for this reason diagnosis is often delayed. A disease of protean manifestations, amoebiasis may present many perplexing problems. A case is reported here of amoebic colitis presenting as a surgical emergency with the unusual feature of a fulminating necrotizing enteritis.

\section{CASE REPORT}

S.F.B., a labourer aged 56, was admitted to the Radcliffe Infirmary as an emergency in February 1964. One month before admission he had an attack, lasting a week, of generalized dull abdominal ache and diarrhoea. He felt vaguely unwell after this episode, and $\mathbf{1 0}$ days later the abdominal pain returned, now localized in the left iliac fossa and associated first with nausea and vomiting, later with diarrhoea. His bowels were open three to four times daily and at no time did he pass blood or slime.

He had suffered from rheumatoid arthritis for 10 years. There was no previous history of dysentery and he had never been out of Europe.

On examination, he looked ill and clinically dehydrated (pulse, $100 / \mathrm{min}$., temperature, $100 \cdot 2^{\circ} \mathrm{F}$, B.P., $100 / 65$ ). There were signs of peritonitis, most marked in the left iliac fossa, with absent bowel sounds. Rectal examination revealed tenderness but no mass.

A diagnosis was made of perforated diverticulitis with a probable differential diagnosis of mesenteric vascular occlusion.

A chest radiograph was normal; a plain radiograph of the abdomen showed fluid levels in small and large bowels with absent psoas shadows. Haemoglobin was $15 \cdot 2 \mathrm{~g} . / 100 \mathrm{ml}$., P.C.V. $48 \%$, W.B.C.s $15,700 /$ c. mm., with a preponderance of polymorphs. Electrolyte concentrations were $\mathrm{Na} 136 \mathrm{mEq} . / 1$, K $3.5 \mathrm{mEq} . / 1$., and urea 37 $\mathrm{mg} . / 100 \mathrm{ml}$.

OPERATION The abdomen was explored through a left lower paramedian incision revealing a large quantity of turbid fluid. The left side of the colon was dilated, oedematous, and adherent to the parietal peritoneum. The colon was so friable that it disintegrated on gentle palpation, necessitating a rapid left hemicolectomy to prevent overwhelming contamination. The remainder of the colon was then examined more closely. The transverse and ascending colon had a bluish tinge and the superficial vessels presented a beaded appearance suggesting thrombosis, but they bled freely when cut. Pulsation was feeble in the main colic arteries. The viability of the remaining colon seemed doubtful and the excision was extended to subtotal colectomy with ileostomy and exteriorization of the distal end of the sigmoid colon. The only other abnormality found was a soft mass on the superior surface of the liver which was thought at the time to be an angioma. This was probably the abscess found at necropsy. The ileum was found to contain pus, a smear showing Gram-positive cocci, and later culture report was of Bact. coli and Cl. welchii.

At the conclusion of the operation the diagnosis was thought to be staphylococcal enteritis associated with fulminating ulcerative colitis.

PROGRESS The patient was treated with intravenous fluids and nasogastric aspiration. He was given intramuscular cloxacillin $250 \mathrm{mg}$. q.d.s. and streptomycin 0.5 g. b.d.; staphylococcalantitoxin 20,000 u. intravenously; anti-gas gangrene serum $2,500 \mathrm{u}$. intravenously, and antitetanus serum 1,500 u. After 24 hours the blood pressure fell to $80 \mathrm{~mm}$. systolic and could be restored only with intravenous hydrocortisone. For three days the patient's condition steadily improved, the blood pressure being maintained with decreasing doses of hydrocortisone while the ileostomy functioned satisfactorily. On the fourth day after operation the patient collapsed quite suddenly and died.

The cause of death was thought to be toxaemia due to overwhelming bacterial infection.

\section{PATHOLOGY}

COLECTOMY SPECIMEN The colectomy specimen was received in two parts, namely, caecum, appendix, and 


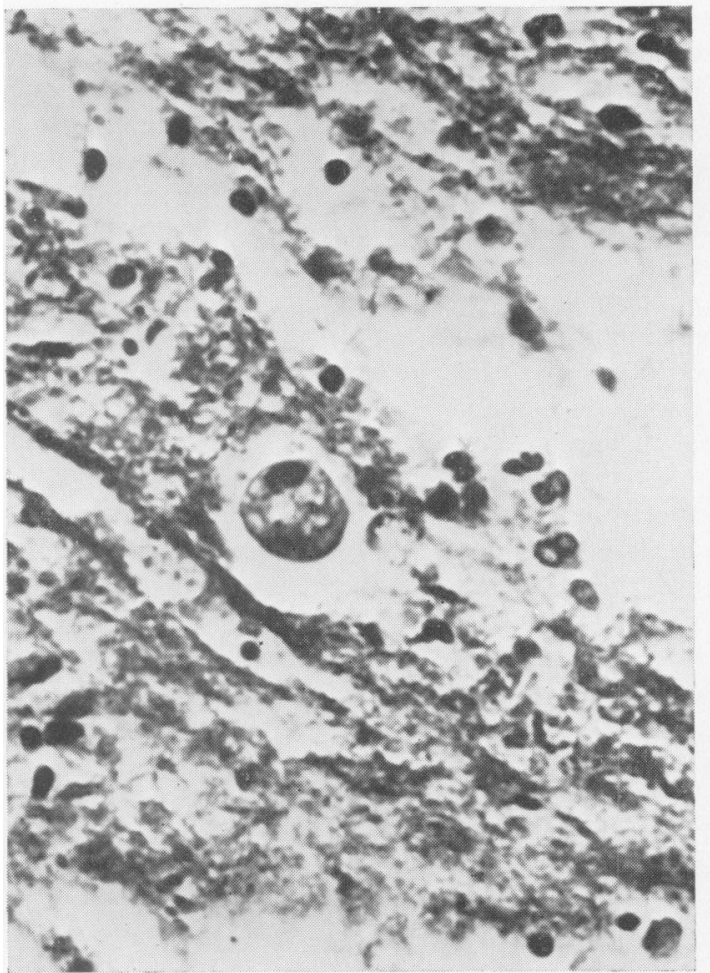

FIG. 1a

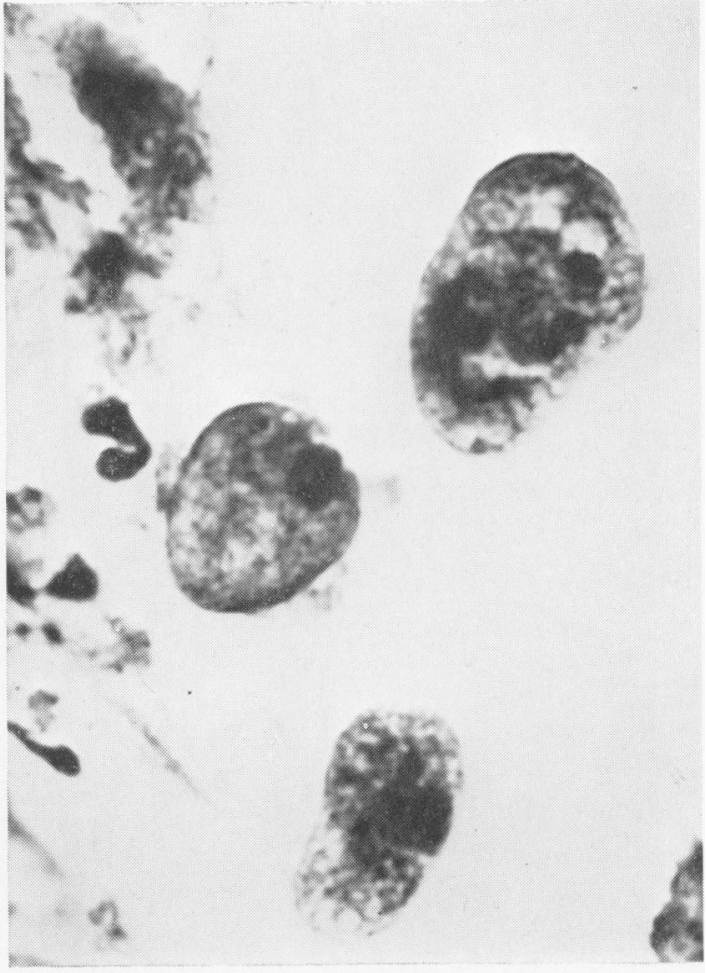

FIG. $1 \mathrm{~b}$

FIG. 1a AND 1b. Photomicrographs of amoebae on the wall of the colon. Fig. $1 a \times 450$, Fig. $1 b \times 1,120$.

ascending colon, measuring $27 \mathrm{~cm}$. in length, and transverse and descending colon, measuring $45 \mathrm{~cm}$. in length.

The normal mucosal lining was almost entirely replaced by a thick layer of necrotic debris and the lumen of the bowel contained a large amount of dark, foul-smelling pus. Similar material was present in the deeper muscle layers and there were several small pericolic abscesses to which portions of necrotic omentum were loosely attached.

Histological examination confirmed extensive loss of the mucous membrane although a few shreds of degenerate epithelium were present in the superficial parts of a thick layer composed of amorphous necrotic debris, fibrin, extravasated red blood cells, and mixed inflammatory cells. Numerous round, nucleated structures were also observed in this area which were identified as amoebae (Fig. 1). These measured about $20 \mu$ in diameter and many of them contained ingested cellular debris and erythrocytes. This inflammatory infiltrate was not particularly heavy and consisted mainly of polymorphs, lymphocytes, and plasma cells; macrophages were prominent in some areas. These changes were most marked in the superficial layers of the bowel and the amoebae were apparently confined to the necrotic slough, more being observed in the deeper layers. Inflammatory exudate was, however, also present within the muscle coats, forming small abscesses in some areas. The muscle fibres were oedematous but showed little active destruction. Deeper extension into the pericolic fat with further abscess formation was apparent in some regions.

\section{POST-MORTEM EXAMINATION}

A necropsy was performed 30 hours after death and the principal findings were that the lungs were congested and oedematous with no consolidation or infarction, and in the heart, marked sclerosis of the coronary arterial tree with many narrowed segments but no occlusion.

A small quantity of purulent fluid was found in the peritoneal cavity, and a few tiny, superficial abscesses in the distal segment of the ileum. There were necrotic, sloughing areas in the rectum and sigmoid colon similar to those in the resected portion of bowel (Fig. 2). The liver was enlarged $(2,170$ g.), smooth and pale; a single abscess, $3 \mathrm{~cm}$. in diameter, was found in the left lobe with no deep extension into the liver or adjacent structures. This abscess contained about $2 \mathrm{ml}$. of thick purulent material which was sterile on culture. A stained smear showed amorphous debris and a few pus cells, but no amoebae were seen.

\section{DISCUSSION}

This case presents several unusual features. Apart 


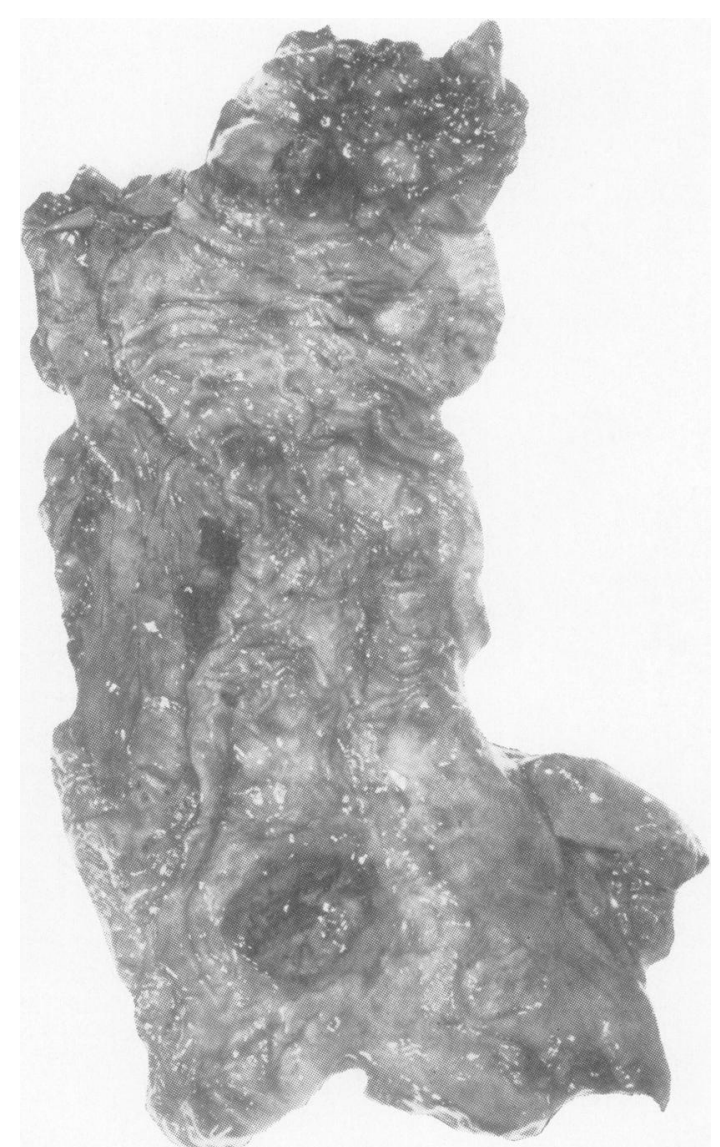

FIG. 2. Photograph of remaining sigmoid colon removed at necropsy showing necrosis and massive ulcer.

from a trip to France 20 years previously the patient had never left England. The amoebiasis appeared to be of recent origin, although the source could not be established. Amoebiasis is, however, a 'ubiquitous disease not confined to the tropics' (Radke, 1955), and its occurrence in Great Britain in individuals who have never been abroad is well documented (Morton, Neal, and Sage, 1951; Manson-Bahr, 1960).

Owing to the inevitable technical delay in the preparation of gangrenous bowel for histology, the diagnosis was not considered until after death, and even at necropsy when this possibility was discussed, it was then disputed. It might be suggested that the primary lesion was an acute bacterial enterocolitis in the presence of a coincidental amoebiasis, and indeed studies of staphylococcal enterocolitis (Prohaska, Long, and Nelson, 1956) and necrotizing enteritis due to Clostridium welchii (Gordon, 1936) show that such infections usually occur only in bowel with an abnormal flora. A few cases of spontaneous enteritis due to clostridia have also been described (Zeissler and Rassfeld-Sternberg, 1949; Jarkowski and Wolf, 1962). Bacterial infection superimposed on amoebic colitis is not uncommon, and may well have contributed to the fulminating course of the disease, which is rare in a previously healthy individual (Adams and Maegraith, 1964). In our case, however, histology revealed only a slight inflammatory infiltrate with relatively few polymorphs, supporting our contention that the primary lesion was amoebiasis, the bacterial infection being secondary.

Surgery in untreated amoebiasis is excessively dangerous (Fairley, Woodruff, and Walters, 1961) and it is possible that the addition of amoebicidal drugs might have saved the life of our patient. Lack of familiarity with the manifestations of amoebiasis prevented its early diagnosis, although the initial surgical management would have had to be the same even if this diagnosis had been considered before operation. Wright (1966) found that 63 patients had been treated for amoebiasis at the Radcliffe Infirmary between 1938 and 1964, and has demonstrated the difficulties in diagnosis encountered in Britain. Other practitioners in the United Kingdom may also feel a lack of familiarity with amoebiasis if they have not made a particular study of tropical diseases, and the possibility must be kept in mind even in patients who have never been abroad.

Kean, Gilmore, and Van Stone (1956) studied 148 fatal cases of amoebiasis from the Armed Forces Institute of Pathology in the U.S.A. and found that $16 \%$ died within a fortnight of the onset of the disease. Fatal cases tended to deteriorate rapidly, and $80 \%$ of the total mortality occurred within the first six months. These findings were substantially in agreement with Clark's (1925) whose similar investigations showed that the commonest cause of death was intestinal complications, the chief of which was perforation. The whole colon is commonly involved (40\% of Clark's cases), perforations often being multiple. Adams and Maegraith (1964) describe either frank perforation or a slow leak through extensively diseased bowel causing peritonitis. Our case falls into this latter group, there being no overt perforation at the time of operation although almost certainly this would have ensued without surgical intervention.

\section{SUMMARY}

A case of ntcrotizing amoebic colitis with superimposed bacillary infection presenting as an acute abdomen is described. The source of the infection is unknown and it was almost certainly acquired in 
Britain. It is emphasized that amoebiasis is not uncommon in those who have never been abroad and its diagnosis in the United Kingdom should be entertained more freely. The case described presented the rare form of fulminating disease leading to death within a month of its onset.

We would like to thank Mr. G. E. Moloney for permission to report this patient who was admitted under his care, and for his help in the preparation of this paper. Dr. A. II. T. Robb-Smith kindly allowed us access to the histological material.

\section{REFERENCES}

Adams, A. R. D., and Maegraith, B. G. (1964). Clinical Tropical Diseases, 3rd ed. Blackwell, Oxford.

Clark, H. C. (1925). The distribution and complications of lesions found in 186 post-mortem examinations. Amer. J. trop. Med., $5,157-171$.
Fairley, N. H., Woodruff, A. W., and Walters, J. H. (1961). Recent Advances in Tropical Medicine, 3rd ed. Churchill, London.

Gordon, S. (1936). B. Welchii infection complicating conservatively treated appendiceal abscess. Brit. J. Surg., 24, 399-401.

Jarkowski, T. L., and Wolf, P. L. (1962). Unusual gas bacillus infections including necrotic enteritis. J. Amer. med. Ass., 181, $845-850$

Kean, B. H., Gilmore, H. R., Jr., and Van Stone, W. W. (1956). Fatal amebiasis: report of 148 fatal cases from the Armed Forces Institute of Pathology. Ann. intern. Med., 44, 831-843.

Manson-Bahr, P. H. (1960). Manson's Tropical Diseases, edited by P. H. Manson-Bahr, 15th ed. Cassell, London.

Morton, T. C., Neal, R. A., and Sage, M. (1951). Indigenousamoebiasis in Britain. Lancet, 1, 766-769.

Prohaska, J. van., Long, E. T., and Nelson, T. S. (1956). Pseudomembranous enterocolitis. Arch.' Surg., 72, 977-983.

Radke, R. A. (1955). Ameboma of the intestine: an analysis of the disease as presented in 78 collected and 41 previously unreported cases. Ann. intern. Med., 43, 1048-1066.

Wright, R. (1966) Amoebiasis-a diagnostic problem in Great Britain. Brit. med. J., 1, 957-959.

Zeissler, J., and Rassfeld-Sternberg, L. (1949). Enteritis necroticans due to clostridium Welchii type F. Brit. med. J., 1, 267-269. 